\title{
Acoustical parameters of polyethylene glycol/water mixtures
}

\author{
A VARADA RAJULU and P MABU SAB \\ Department of Polymer Science and Technology, Sri Krishnadevaraya University, \\ Anantapur 515003, India \\ MS received 12 September 1994; revised 17 February 1995
}

\begin{abstract}
Ultrasonic velocity $(v)$ and density $(d)$ have been measured for polyethylene glycol/water mixtures at $30^{\circ} \mathrm{C}$. The adiabatic compressibility $\left(\beta_{\mathrm{ad}}\right)$, molar compressibility $(\beta)$, specific acoustic impedance $(Z)$, Rao number $(R)$ and van der Waals constant $(b)$ have been computed. The variations of $v, d, \beta_{\mathrm{ad}}, \beta, Z, R$ and $b$ with mole ratio of water/ether group oxygen have been studied. The association between the components and the formation of tetrahydrate have been reported.
\end{abstract}

Keywords. Polyethylene glycol; acoustical parameters; van der Waals constant; molecular association; liquid mixtures.

\section{Introduction}

The variation of ultrasonic velocity and adiabatic compressibility of dilute aqueous solutions of solid polyethylene glycol (PEG) with concentration was studied by Gerecze (1977) who concluded that there was no solute-solvent interaction. Recently Graham and Chen (1993) studied the interaction of liquid and solid PEG (PEG-300, 400,1000 and 3330) with water and revealed the formation of tetrahydrate in low molecular weight PEG $(\mathrm{MW}<600)$ and tri- and hexahydrate formation for higher molecular weight PEGs using density data. In the present work we have measured the ultrasonic velocity and density of PEG-200 (MW 200) at $30^{\circ} \mathrm{C}$. The acoustical parameters molar compressibility $\beta$, specific acoustic impedance $Z$ and Rao number $R$ have been computed. The van der Waals constant $b$ has also been determined by ultrasonic method. The variation of these parameters with the ratio of moles of water per ether oxygen in the PEG has been studied. We selected PEG as it has applications as hydrogel and PEG-200 was not covered in the interaction studies of Graham and Chen (1993).

\section{Experimental}

PEG-200 (S D Chemicals) was dried under vacuum at $65^{\circ} \mathrm{C}$ for $24 \mathrm{~h}$ before use. To known weight of the dry PEG in $50 \mathrm{ml}$ standard flasks the appropriate amounts of double distilled water was added to give the desired ratio of moles of water per ether oxygen in the PEG and test samples with $\mathrm{H}_{2} \mathrm{O} /-\mathrm{CH}_{2}-\mathrm{CH}_{2}-\mathrm{O}$ of 1.5, 2.0, 2.5, $\cdots, 7 \cdot 0$ were prepared. These mixtures were maintained in the oven for $6 \mathrm{~h}$ at $65^{\circ} \mathrm{C}$ to obtain thorough mixing, cooled to room temperature, and allowed to attain equilibrium for several days in sealed containers. The ultrasonic velocities of these mixtures were measured with a $2 \mathrm{MHz}$ variable path interferometer at $30^{\circ} \mathrm{C}$ as described by Varada Rajulu et al (1990). The densities were measured with a precalibrated density bottle using a water bath thermostated at $30^{\circ} \mathrm{C}$. 


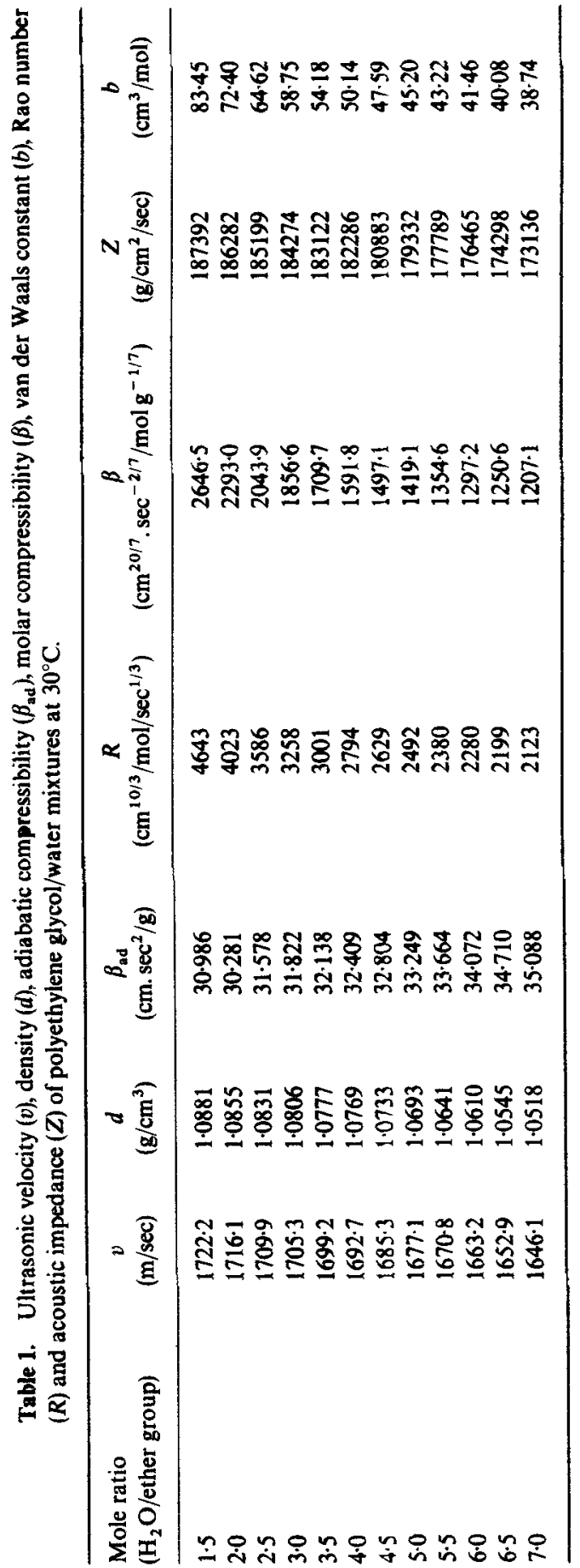




\section{Results and discussion}

The measured values of ultrasonic velocity $(v)$ and density $(d)$ are presented in table 1 . The adiabatic compressibility $\left(\beta_{\text {ad }}\right)$ was calculated using the relation (Varada Rajulu et al 1990)

$$
\beta_{\mathrm{ad}}=\left(d v^{2}\right)^{-1}
$$

The Rao number $(R)$ was calculated using the relation (Rao et al 1989)

$$
R=(M / d) v^{1 / 3},
$$

where $M$ is the molecular weight of the liquid mixture given by

$$
M=\left(n_{1} M_{1}+n_{2} M_{2}\right) /\left(n_{1}+n_{2}\right)
$$

where $M_{1}$ and $M_{2}$ are the molecular weights and $n_{1}$ and $n_{2}$ are the moles of the components comprising the mixture. The molar compressibility $(\beta)$ was calculated using Wada's (1949) relation

$$
\beta=(M / d)\left(\beta_{\text {ad }}\right)^{-1 / 7}
$$

The specific acoustic impedance $(Z)$ was calculated using the relation

$$
Z=(d v)
$$

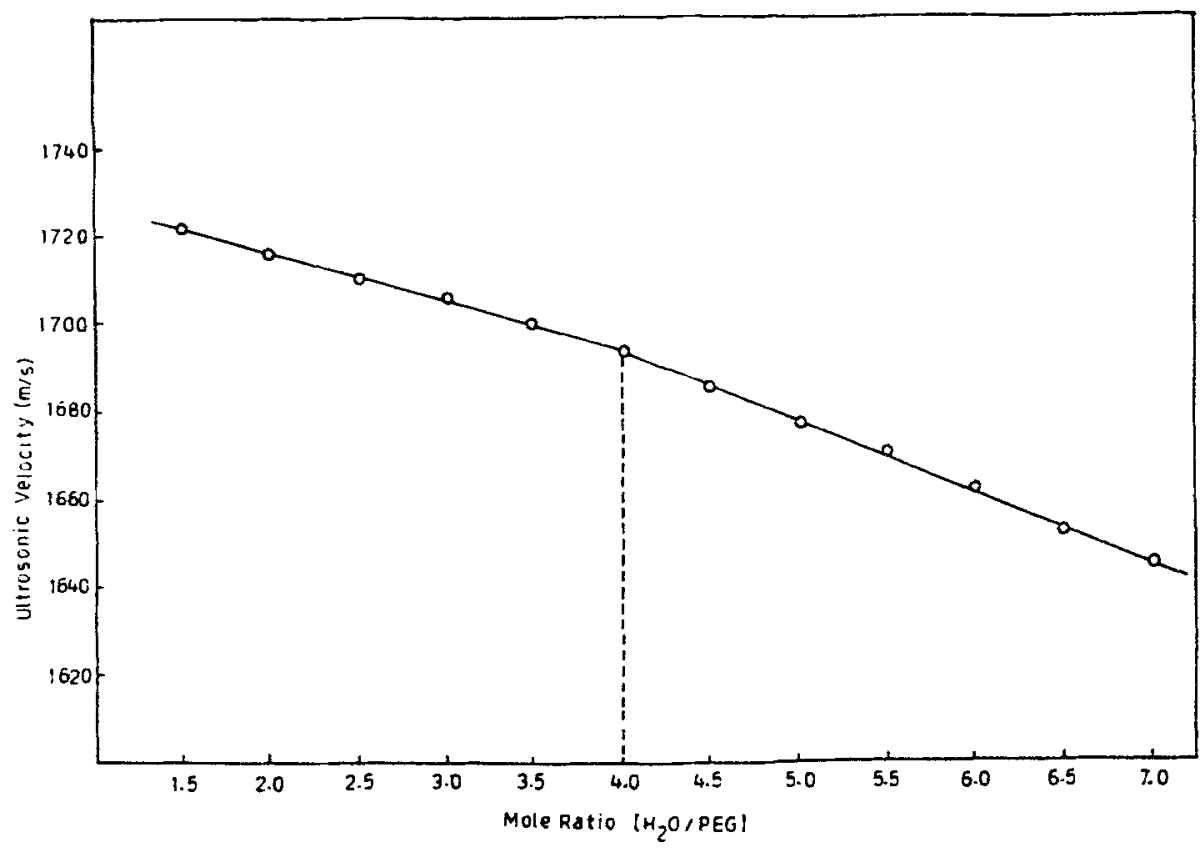

Figure 1. Variation of ultrasonic velocity $(v)$ with moles of water per ether group in PEG-200/water mixtures at $30^{\circ} \mathrm{C}$. 
The van der Waals constant $(b)$ was calculated using the measured values of $v$ and $d$ from the relation (Vigoureux 1952)

$$
b=(M / d)\left[1-\left(R T / M v^{2}\right) \sqrt{1+\left(M v^{2} / 3 R T\right)}-1\right] .
$$

Though (2) and (4) are empirical and additive in nature, (1) which has a semiempirical origin soon found theoretical support (Blitz 1967). Similarly (5) is written considering its anology to the mechanical and electrical impedance without reactive component (Blitz 1967). Equation (6) is semiempirical in nature (Flugge 1961).

The measured values of $v$ and $d$ and the computed values of $\beta_{\mathrm{ad}}, R, Z, \beta$ and $b$ are given in table 1 . The variation of $v, d, \beta_{\text {ad }}, \beta, R, Z$ and $b$ with mole ratio of $\mathrm{H}_{2} \mathrm{O}$ /ether group is shown in figures $1,2,3,4,5,6$ and 7 respectively. From figures $1-3$ and 6 it is evident that the variation of $v, d, \beta_{\text {ad }}$ and $Z$ show two linear portions with different slopes with a break at a mole ratio of 4 . A similar observation was made by Graham and Chen (1993) in the case of PEG (MW < 600) by density measurements and this was attributed to the formation of tetrahydrate.

Nomoto (1953) established the validity of (2), (4) and (6) in a large number of liquid mixtures and stated that for unassociated components in the liquid mixtures the variation of $R, \beta$ and $b$ with mole ratio will be linear. In the present study a smooth nonlinear relation is observed indicating that association exists between PEG and water. The nonlinear behaviour is probably due to the fact that there will be a change of molecular weight due to the association and the weight of the associated groups is

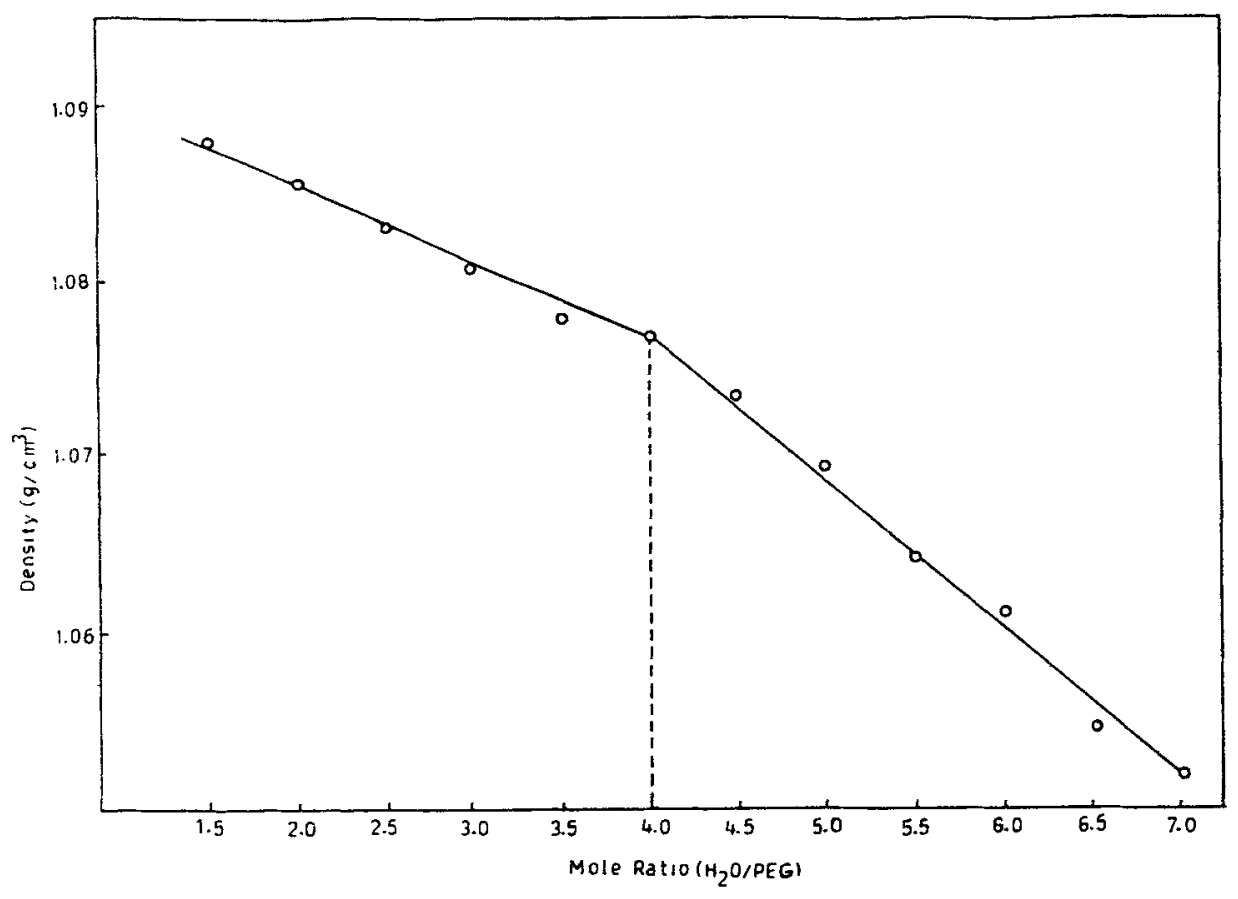

Figure 2. Variation of density $(d)$ with moles of water per ether group in PEG-200/water mixtures at $30^{\circ} \mathrm{C}$. 


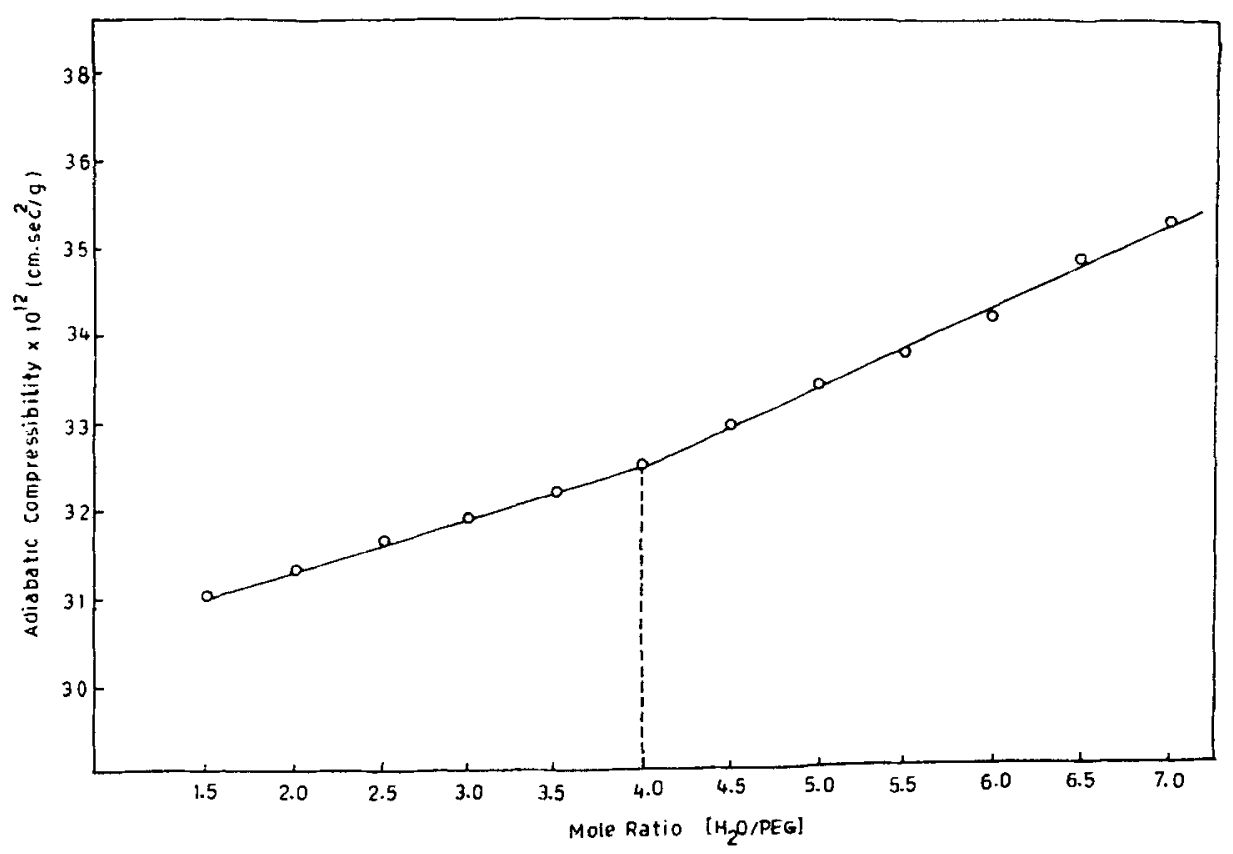

Figure 3. Variation of adiabatic compressibility $\left(\beta_{\mathrm{ad}}\right)$ with moles of water per ether group in PEG-200/water mixtures at $30^{\circ} \mathrm{C}$.

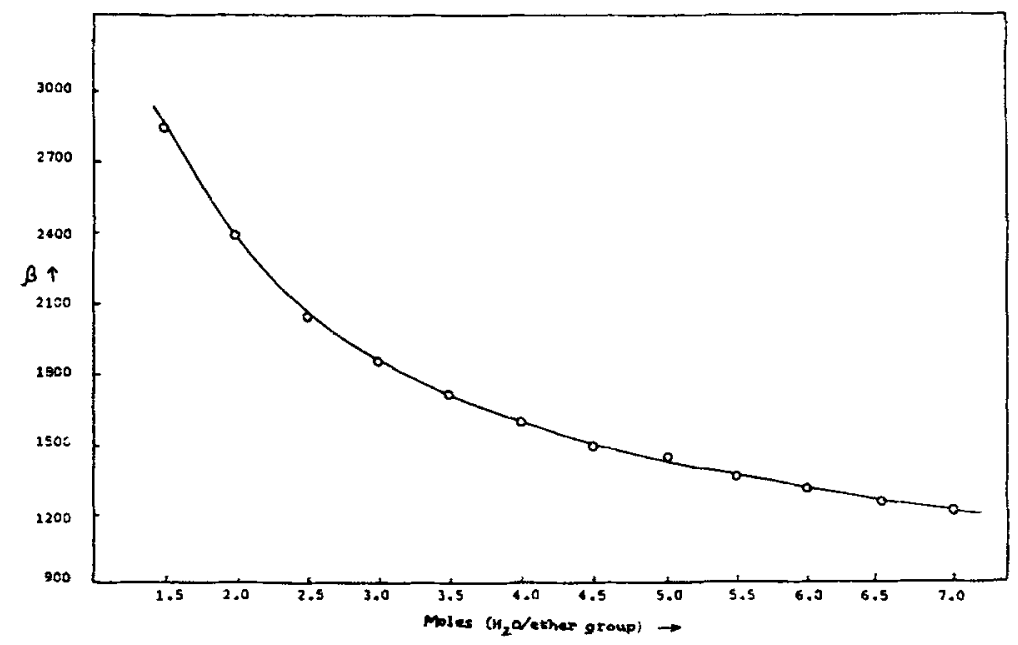

Figure 4. Variation of molar compressibility $(\beta)$ with moles of water per ether group in PEG-200/water mixtures at $30^{\circ} \mathrm{C}$.

different from that of the components (Nomoto 1953). Further the smooth nonlinear behaviour is observed only in the case of the variation of parameters $\beta, R$ and $b$ which involve the molecular weight term. Similar observations were also made by Chowdoji Rao et al (1990) and Varada Rajulu et al (1990) in the case of polyvinyl pyrrolidone 


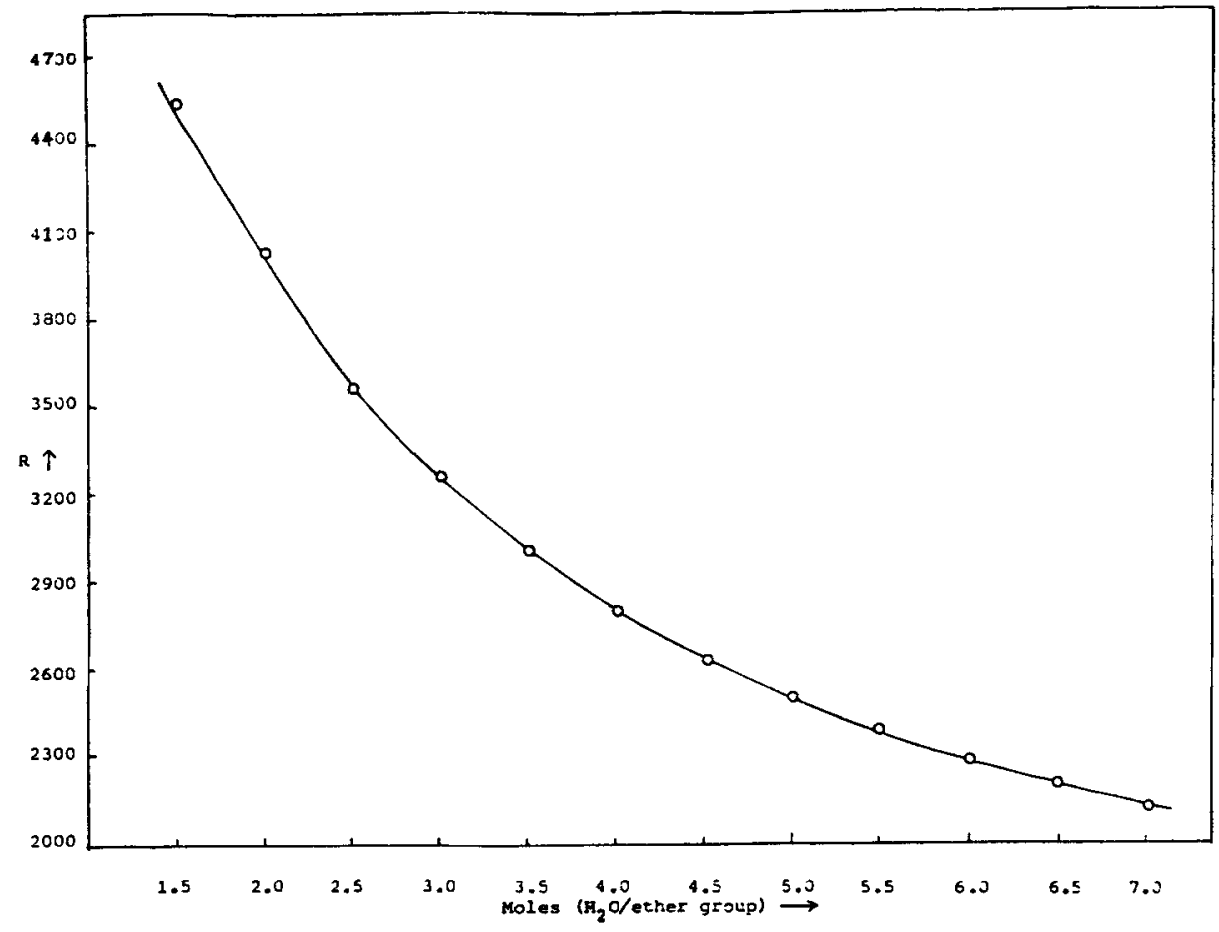

Figure 5. Variation of Rao constant $(R)$ with moles of water per ether group in PEG$200 /$ water mixtures at $30^{\circ} \mathrm{C}$.

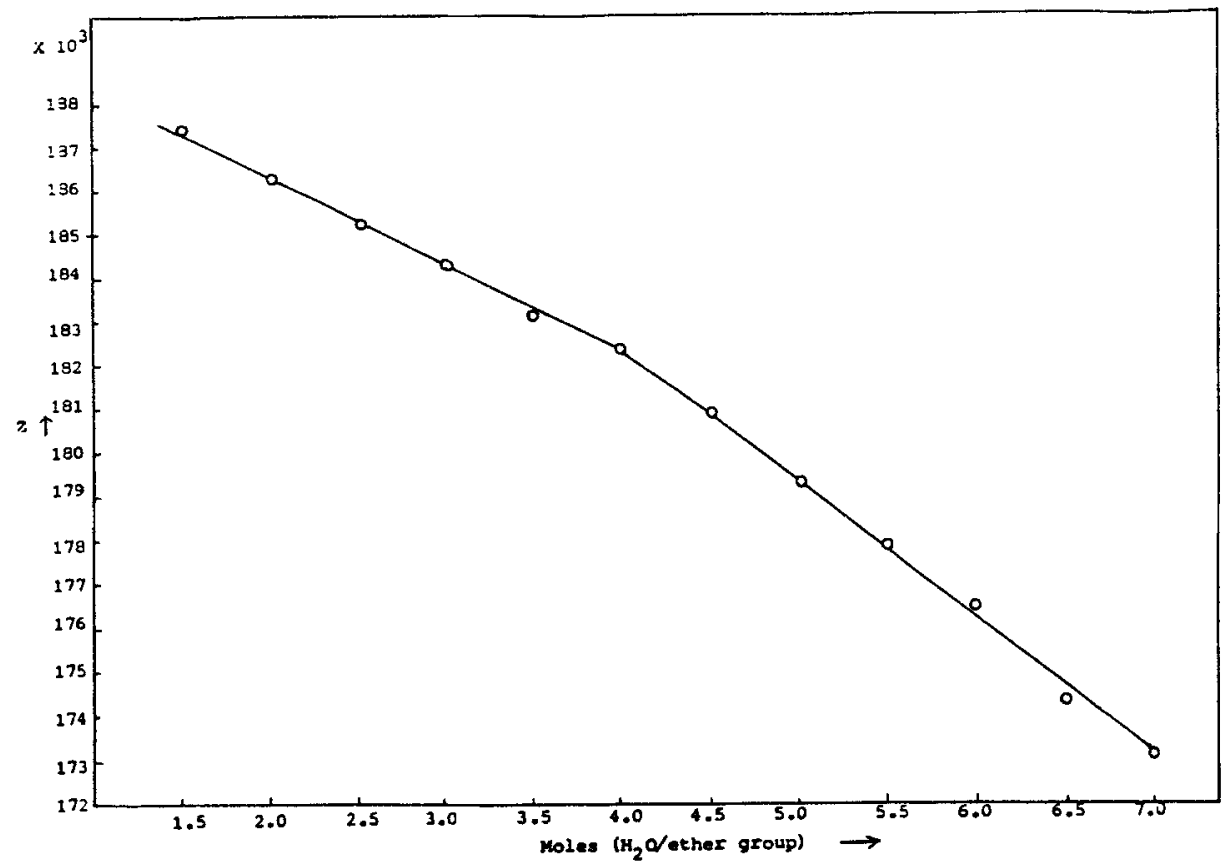

Figure 6. Variation of acoustic impedance $(Z)$ with moles of water per ether group in PEG-200/water mixtures at $30^{\circ} \mathrm{C}$. 


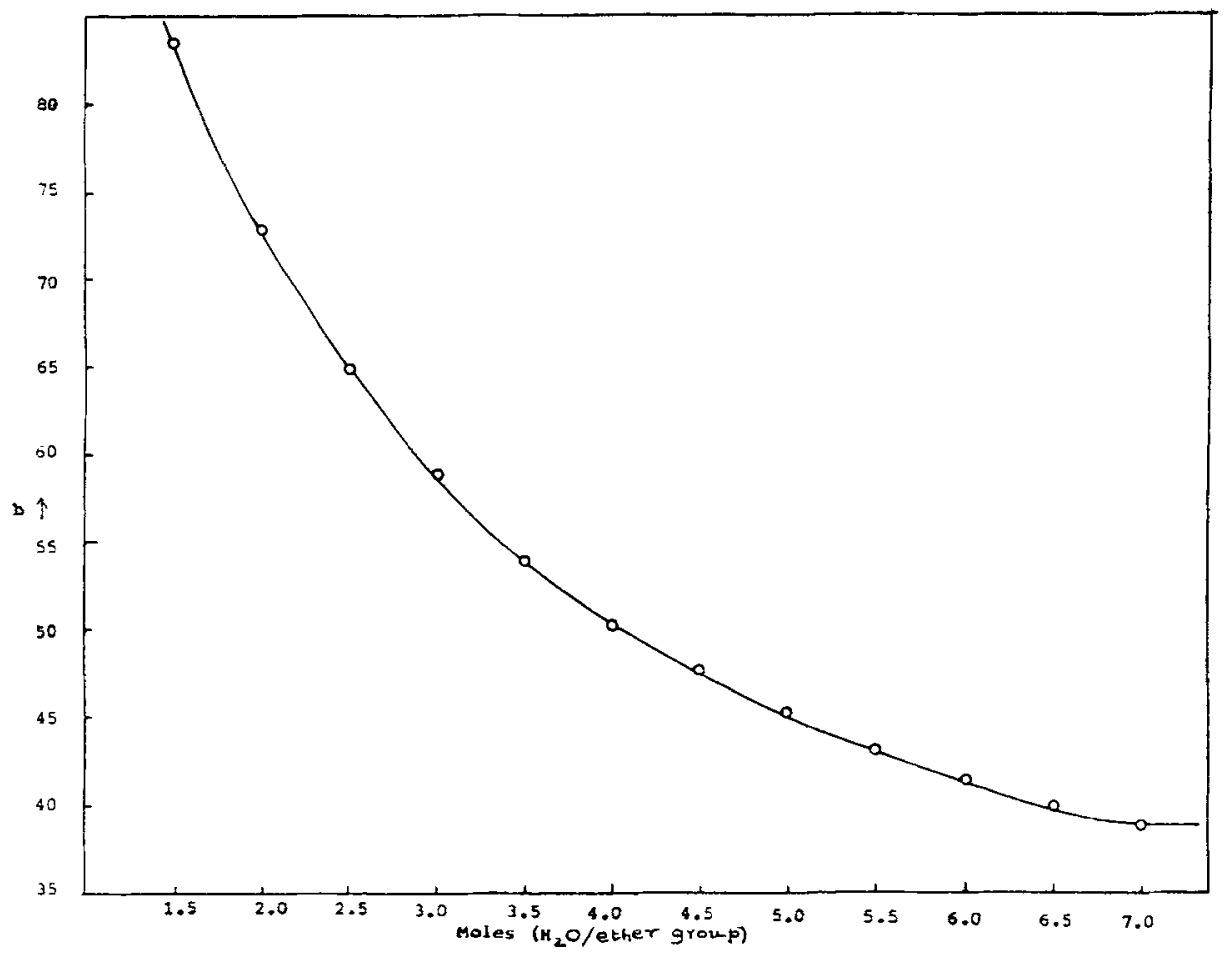

Figure 7. Variation of van der Waals constant $(b)$ with moles of water per ether group in PEG-200/water mixtures at $30^{\circ} \mathrm{C}$.

solutions. These observations help us to confirm the association. Thus the association between PEG-200 and water and the tetrahydrate formation can be confirmed using ultrasonic velocity data in the present case. The interaction of PEG $(M W>1000)$ with water was not observed by Gerecze (1977) as the solution concentration was maintained very low.

\section{References}

Blitz J 1967 in Fundamentals of ultrasonics (London: Butterworth Publishing Co. Ltd.) Chowdoji Rao K, Venkata Naidu S and Varada Rajulu A 1990 Eur. Polym. J. 26657

Flugge S 1961 in Encyclopedia of physics (Berlin: Springer Verlag) Vol. XI/1

Gerecze N G 1977 Acustica 3851

Graham N B and Chen C F 1993 Eur. Polym. J. 29149

Nomoto O 1953 J. Chem. Phys. 21950

Rao K Ch, Rajulu A V and Naidu S V 1989 Acta Polymerica 40743

Varada Rajulu A, Chowdoji Rao K and Venkata Naidu S 1990 J. Pure Appl. Ultrason. 12115

Vigoureux P 1952 in Ultrasonics (London: Chapman and Hall)

Wada Y 1949 J. Phys. Soc. Jpn. 4280 